\title{
Препериметрическая глаукома (обзор литературы)
}

\author{
Мачехин В. А. ${ }^{1,2}$ \\ д.м.н., главный научный консультант ${ }^{1}$, профессор, кафедра офтальмологии ${ }^{2}$ \\ Фабрикантов О. Л., ${ }^{1,2}$ \\ д.м.н., директор ${ }^{1}$, заведующий, кафедра офтальмологии ${ }^{2}$ \\ Львов В. А. ${ }^{1}$ \\ врач-офтальмолог \\ 1 - Тамбовский филиал ФГАУ «НМИЦ «МНТК «Микрохирургия глаза» им. академика С.Н. Федорова» \\ Минздрава России, Тамбов, Российская Федерация \\ 2 - ФГБОУ ВПО «Тамбовский государственный университет имени Г.Р. Державина», Медицинский \\ институт, Тамбов, Российская Федерация
}

\begin{abstract}
Автор для корреспонденции: Мачехин Владимир Александрович; e-mail: naukatmb@mail.ru Финансирование. Исследование не имело спонсорской поддержки.

Конфликт интересов. Авторы заявляют об отсутствии конфликта интересов.
\end{abstract}

Аннотация

Термин «препериметрическая глаукома» впервые появился в зарубежной литературе в самом конце 20 века. Предыдущий опыт анализа диска зрительного нерва основывался в основном на офтальмоскопии, фотографировании и стереофотографировании, планиметрии и других трудоемких методах исследования при глаукоме. Появление современных, более точных методов диагностики, позволило впервые разделить качественные (субъективные) и количественные (объективные) критерии оценки диска зрительного нерва и прилежащей сетчатки. Потребовались годы, прежде чем офтальмологи начали осмысливать значение этого термина и его роль в глаукоме. Этому вопросу и посвящен данный обзор литературы, представленный в хронологическом порядке.

Ключевые слова: офтальмология, препериметрическая глаукома, диск зрительного нерва

doi: $10.29234 / 2308-9113-2019-7-2-59-80$

На рубеже 20 и 21 века, в связи с бурным научно-техническим развитием во всех областях нашей жизни, включая и медицину, заметно изменились устоявшиеся десятилетиями приоритеты и представления о глаукоме.

Во-первых, было разработано и стало доступным для широкого круга офтальмологов уникальное оборудование, позволяющее не только выявлять патологические изменения, происходящие в глазах при развитии глаукомы, но и с большой точностью проводить количественную оценку этих изменений (компьютерная периметрия центрального поля зрения, лазерная и оптическая когерентная томография диска зрительного нерва и сетчатки и другие методы исследования).

Во-вторых, эти новые методы исследования дали возможность раннего выявления глаукомы и четкого определения ее стадийности, определив главными симптомам глаукомы патологические изменения диска зрительного нерва с окружающей его 
сетчаткой в сочетании с изменениями центрального поля зрения, которое получило название глаукомной оптической нейропатии (ГОН). Оно широко обсуждалось на международной конференции глаукоматологов в Базеле (1999) и официально было принято к руководству в Париже в 2004 году. При этом подчеркивалось, что структурные изменения диска в большинстве случаев опережают функциональные, а последние более четко выявляют динамику процесса. Это заключение было основано на результатах экспериментальных и клинических исследований офтальмологов 80-90-х годов.

Исходя из этого, появление термина «препериметрическая глаукома» вряд ли можно назвать случайным, поскольку это была попытка определить более точное ее место в процессе развития глаукомы. Впервые он появился в зарубежной литературе в самом конце 20 века (C.Y. Mardin, F.K. Horn, J.B.Jonas, W.M. Budde, 1999) [37], спорадически появлялся в статьях последующего десятилетия $[12,20,23]$, но наибольшее количество работ на эту тему стало публиковаться как за рубежом, так и в России в последние 5-8 лет.

В чем заключалось отличие их подхода для выявления глаукомы от предыдущего 30-40летнего опыта офтальмологов? Во-первых, несмотря на большие достижения в изучении ДЗН с помощью офтальмоскопии, стереофотографирования, планиметрии и других трудоемких методов исследования, они оставались по сути квалификационными, а не квантитативными методами. Во-вторых, как правило, проводилось дифференцирование между глаукомными и нормальными глазами, между глаукомой и офтальмогипертензией, между глаукомой и пациентами с подозрением на глаукому.

Учитывая предыдущий опыт анализа диска зрительного нерва при глаукоме, Mardin et al. решили разделить качественные и количественные критерии оценки диска зрительного нерва и прилежащей сетчатки. К качественным критериям были отнесены такие, как изменение формы и величины диска, локальное или диффузное углубление и расширение экскавации, щелевидные кровоизлияния по краю диска, хориоретинальная атрофия в перипапиллярной области, фокальное и диффузное уменьшение диаметра артериол сетчатки и локализованные и диффузные потери слоя нервных волокон сетчатки $[15,19,38,47,52]$. В этих исследованиях качественные критерии в основном использовались для демонстрации наличия глаукоматозного повреждения зрительного нерва.

K количественным показателям относили такие параметры, как площадь и объем нейроретинального пояска (НРП), площадь и объем экскавации ДЗН, а также толщину слоя нервных волокон сетчатки по краю диска (RNFL).

Целью исследования было оценить, являются ли количественные морфологические исследования параметров диска, измеренные конфокальной сканирующей лазерной томографией, полезными для раннего выявления глаукоматозных изменений ДзН в глазах с повышенным внутриглазным давлением, аномальным внешним видом диска и нормальными полями зрения. Для этого был проведен анализ 50 нормальных глаз, 61 
глаза с глаукомой и 102 глаз с препериметрической глаукомой с использованием Heidelberg retina tomograph (HRT-2.01) и компьютерного периметра Octopus G1. Почти все исследованные параметры ДЗН значительно различались $(P<0,05)$ между нормальными глазами и глазами с препериметрической глаукомой с выраженным перекрытием параметров между двумя группами. В соответствии с перекрывающимися значениями параметров, чувствительность и специфичность параметров были относительно низкими в тех случаях, когда оценивалось различие в группе нормы и препериметрической глаукомы, (хотя, судя по цифровым данным, это различие практически отсутствует). Делается вывод, что из-за ярко выраженного перекрытия величины параметров между группами конфокальная сканирующая лазерная томография ДЗН имеет относительно низкую диагностическую способность для дифференциации нормальных глаз и глаз с препериметрической глаукомой. Одной из причин, по мнению авторов, может быть биологическая индивидуальность параметров ДзН.

G. Hollo et al. [23] решили оценить возможности лазерной поляриметрии, стандартной периметрии центрального поля зрения (SAP) и frequency-doubling technology (FDT) для раннего выявления прогрессирования препериметрической первичной открытоугольной глаукомы. На небольшом клиническом материале (22 глаза 11 пациентов в возрасте 41-60 лет) было проведено наблюдение в течение 1 года. Группа с препериметрической глаукомой была составлена в основном по качественным признакам: стереоскопическая картина диска зрительного нерва с небольшими его изменениями, которые включали локальные дефекты сетчатки $и$ обнажение поперечных сосудов по краю нейроретинальной границы, перипапиллярную атрофию сетчатки. Все пациенты имели нормальное состояние поля зрения по данным обоих методов и небольшое повышение ВГД (>22 мм рт.ст.), которое у большинства было компенсировано медикаментозно.

Через 12 месяцев не было выявлено статистически достоверных изменений параметров поля зрения и ВГД, в то время как толщина RNFL в верхнем и нижнем секторах сетчатки уменьшилась на $2.77 \mu \mathrm{m}$ and $2.48 \mu \mathrm{m}$ соответственно.

(Несмотря на такое мизерное уменьшение толщины RNFL, авторы делают вывод о том, что лазерная поляриметрия может выявить раннее прогрессирование глаукомы, даже если не наблюдается ухудшение поля зрения).

B. Baraibar et al. [12], также используя лазерную поляриметрию и стереофотографию диска, компьютерную периметрию по программе Humphry Field Analyser 24-2, провели сравнение результатов исследования толщины перипапиллярной сетчатки в 607 нормальных глазах и в 63 глазах с препериметрической глаукомой. Не приводя цифровые значения параметров, используя только РОК-анализ, авторы сделали вывод о том, что индекс нервных волокон был значительно меньше в глазах с препериметрической глаукомой на 6 и 12 часах по сравнению с нормальными глазами и что лазерная поляриметрия обладают лучшими диагностическими возможностями для выявления различий между нормой и препериметрической глаукомой. 
K подобному выводу пришли H.Kim et al. [29], использовав лазерную поляриметрию, оптическую когерентную томографию (Stratus OCT) и стандартную автоматизированную периметрию (SAP) при сравнении 60 здоровых и 60 глаз с препериметрической глаукомой. Они представили конкретные цифры средней толщины перипапиллярной сетчатки (RNFL), которые были заметно меньше в глазах с препериметрической глаукомой по сравнению с нормальными глазами при лазерной поляриметрии (49,0 $\mu \mathrm{m}$ и 59,4 $\mu \mathrm{m}$ $\mathrm{P}<0,01)$ и $(86,4 \mu \mathrm{m}$ и 106,6 $\mu \mathrm{m}, \mathrm{P}<0,01)$ и по данным ОСТ. Кроме того, было отмечено различие толщины RNFL по секторам в обоих группах, а также более высокая значимость для этого параметра при поляриметрии на 12 часах $(0,905)$, и по данным ОСТ на 7 часах $(0,903)$. Оба метода показали похожую корреляцию в каждом секторе и оба полезны при диагностике препериметрической глаукомы.

A. Ferreras et al. [20] сравнили возможности периметрии с удвоенной частотой (frequencydoubling technology - FDT) и коротковолновой автоматической периметрией (SWAP) для выявлении глаукомы в группе глаз с препериметрической глаукомой (109), которая характеризовалась нормальным SAP и наличием дефектов слоя нервных волокон и структуры диска по данным GDx VCC, Stratus OCT и HRT II. Они установили, что почти в 20\% случаев в глазах с препериметрической глаукомой FDT и SWAP, в отличие от SAP, обнаружили патологические изменения центрального поля зрения.

F. Horn et al. [24] провели исследование 330 пациентов, разделив их на пять групп: норма (97), офтальмогипертензия (54), препериметрическая глаукома (77), ранняя (52) и умеренная (50) глаукома. Целью работы было оценить возможности FDT-периметрии и спектральной оптической томографии (SDOCT) в ранней диагностике глаукомы. Группа пациентов с препериметрической глаукомой, в отличие от истинной глаукомы, имела офтальмоскопическую картину ДзН, похожую на глаукомные изменения, а также диффузную или локальную потерю нейроретинальной ткани, подтвержденную данными ретинотомографии, и совершенно нормальное поле зрения по данным FDT-периметрии. Исследование толщины слоя нервных волокон показало, что результаты в группе с препериметрической глаукомой значительно отличались от группы с нормальными глазами $(81,1 \mu \mathrm{m}$ и $96.6 \mu \mathrm{m}$ соответственно) и в меньшей степени от начальной глаукомы (81,1 $\mu \mathrm{m}$ и 70,0 $\mu \mathrm{m}$ соответственно).

T. Rolle et al. [44] у 116 пациентов с препериметрической глаукомой и 52 здоровых лиц провели исследование комплекса ганглиозных клеток макулярной области сетчатки (GCC) и толщины слоя нервных волокон в перипапиллярной области ДЗН с помощью FD-OCT (RTVue). Оно показало заметное уменьшение всех параметров сетчатки у пациентов с препериметрической глаукомой ( $<<0,0001)$. Авторы не обнаружили каких-либо видимых различий между параметрами перипапиллярной сетчатки и параметрами слоя ганглиозных клеток сетчатки и сделали вывод, что «поскольку не было выявлено преимущества того или иного параметра, то неизвестно какой из них можно использовать для раннего выявления глаукомы». 
В.С. Акопян с соав. [1] провели исследование 128 глаз пациентов, разделив их на 4 группы: 1) 29 здоровых глаз; 2) 32 глаза потенциально высокого риска развития глаукомы (повышенное ВГД более 21 мм рт. ст. или увеличение физиологической экскавации без других признаков глаукомы); 3) 36 глаз с препериметрической глаукомой (глаукомное увеличение экскавации, истончение НРП на разной протяженности и отсутствие изменений полей зрения); 4) 31 глаза с периметрической глаукомой (характерные для глаукомы изменения ДЗН и полей зрения различной степени). Статическая периметрия проводилась с помощью периметра Humphrey Field Analyzer по программе 30-2, оптическая когерентная томография проводилась на приборе RTVue-100 ОСT. Проведя РОК-анализ перипапиллярной сетчатки и комплекса ганглиозных клеток между первой и второй группами $(A U C=0,611)$ первой и третьей группами $(A \cup C=0,600)$, первой и четвертой группами (AUC=0,910) выявили высокую прогностическую значимость только для последней группы, что позволило сделать вывод о том, что исследование параметров перипапиллярных волокон сетчатки может помочь только в диагностике периметрической глаукомы и для ранней диагностики она недостаточно информативна. (Кстати, совершенно непонятно различие между 2 и 3 группами, сформулированными авторами этой работы, а глаза с препериметрической глаукомой практически не отличаются от периметрической по параметрам диска и сетчатки). И только один из индексов комплекса ганглиозных клеток (объем фокальных потерь) в отличие от всех остальных достоверно демонстрирует аномальные значения на более ранней препериметрической стадии заболевании.

Lisboa et al. [36] провели анализ диагностической точности оптической когерентной томографии (SDOCT) для выявления препериметрической глаукомы и сравнили ее с показателями HRT3. Исследовано 134 глаза 88 пациентов с подозрением на глаукому. Все пациенты имели нормальные поля зрения в течение всего срока наблюдения (14 лет) и классифицировались по историям документированных стереофотографических данных о прогрессирующих глаукоматозных изменениях в диске зрительного нерва, которые были выявлены в 48 глазах и были включены в группу препериметрической глаукомы. Остальные 86 глаз без каких-либо признаков прогрессирующего изменения диска составили группу нормы. Сравнение показало, что по данным обоих методов в группе глаз с препериметрической глаукомой наблюдалось заметное ухудшение как параметров диска, так и перипапиллярной сетчатки $(\mathrm{P}<0,001-0,005)$ и только РОК-анализ показал небольшое преимущество ОСТ (AUC=0,70-0,88) по сравнению с параметрами диска $(A \cup C=0,65-0,72)$.

$\mathrm{Na}$ et al. [40] сравнили результаты исследования комплекса ганглиозных клеток, перипапиллярной сетчатки и параметров дЗН для выявления локальных дефектов у пациентов с препериметрической глаукомой (105 глаз) и контрольной группой (68 глаз) с использованием прибора RTVue-100 ОСТ. Как показал РОК-анализ, наилучшие результаты наблюдались в верхнем секторе ганглиозных клеток (AUC=0,84), средней толщины перипапиллярной сетчатки $(\mathrm{AUC}=0,89)$ и параметр cup/disc area для ДзН $(\mathrm{AUC}=0,85)$. 
Толщина комплекса ганглиозных клеток значительно уменьшалась в глазах с препериметрической глаукомой.

J.W. Jeoung et al. [26] сравнили диагностические возможности Cirrus ОСТ и Stratus ОСТ для выявления дефектов в сетчатке в 55 глазах с препериметрической глаукомой и в 55 нормальных глазах. Не было выявлено значительных различий между AUROC в нижнем секторе для Cirrus $(0,728)$ и на 7 часах для Stratus $(0,760)$. Это свидетельствует, что оба метода имеют одинаковый диагностический потенциал при препериметрической глаукоме.

T. Hirashima et al. [21] попытались в 26 глазах с препериметрической глаукомой и в 26 здоровых глазах выявить взаимоотношения между различными структурными изменениями по данным HRT3 и RTVue-100 и периметрическими методами (FDT-MD, FDTPSD, SUP-MD, SUP-PSD). Однако они вынуждены были признать, что структурные и функциональные параметры слабо коррелируют, но могут быть дополнительным методом для выявления дефектов в глазах с препериметрической глаукомой.

Choi J.A., используя программу HFA 24-2, провели сравнение параметров MD и PSD в 122 здоровых глазах и 99 глазах с препериметрической глаукомой и выявили большую значимость параметра PSD (AUC=0,767) по сравнению с MD $(A \cup C=0,619)[16]$. К такому же мнению пришли и другие авторы, используя программу HFA 30-2 [10].

V.Begum et al. [13,14] c помощью Cirrus HD-OC анализировали диагностические возможности комплекса ганглиозных клеток в нормальных глазах (53), в глазах с периметрической (62) и препериметрической глаукомой (21) и сравнивали их с параметрами ДЗН и перипапиллярного слоя сетчатки (RNFL) с помощью AUROC. Параметры ДЗН (rim area, cup/disc, cup vol) и RNFL во всех секторах в группах с препериметрической и периметрической глаукомой с высокой степенью достоверности отличались от нормальных глаз $(\mathrm{P}<0,001)$. В то же время, все параметры ганглиозных клеток, отличаясь от нормы в группе с истинной глаукомой $(P<0,001)$, в группе с препериметрической глаукомой не показали различий от нормы (P = от 0,06 до 0,36).

P. Sriram et al. [51] у 93 пациентов с препериметрической глаукомой и 34 здоровыми глазами провели исследования поля зрения (HFA, SWAP, FDT), зрительно-вызванных потенциалов (ЗВП) и морфометрических изменений ДЗН и перипапиллярной сетчатки (SDOCT и HRT 3). Было установлено, что HRT и ЗВП демонстрируют лучшую чувствительность при идентификации препериметрической глаукомы (50,6\% и 51,8\% соответственно) и значительно выше по сравнению с другими тестами.

B. Seol et al. [48] оценили способность комплекса ганглиозных клеток макулярной области сетчатки у пациентов с миопией без глаукомы (108 глаз) и с миопией в глазах с препериметрической глаукомой (104 глаза) с помощью SD-OCT и сравнили ее с перипапиллярным слоем нервных волокон сетчатки (RNFL) и параметрами ДЗН. И, хотя по 
данным авторов, лучшим параметром при дифференциации этих групп являлся нижневисочный сектор комплекса ганглиозных клеток, (мы, тщательно проанализировав цифровой материал, не нашли явного статистического различия между нормальными глазами и глазами с препериметрической глаукомой при миопии). Это подтверждается и полным сходством таких параметров, как средняя рефракция (-

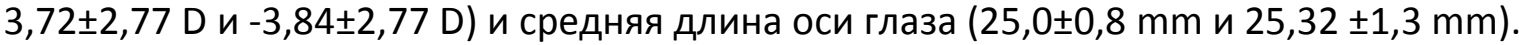

R. Najjar et al. [41] провели исследование саккадических горизональных движений глаз у 16 пациентов с 2-х сторонней препериметрической глаукомой и 16 здоровых человек с помощью инфракрасной окулографии. У пациентов с препериметрической глаукомой наблюдалась пониженная средняя скорость саккад по сравнению с контролем во всех амплитудах представленнных периферических объектов $(P<0,03)$. Саккады, выполненные пациентами с препериметрической глаукомой, были гипометрическими и с уменьшенной амплитудой $(P<0,007)$ и усилением $(P \leq 0,01)$ по сравнению с контрольными. В среднем у пациентов с ППГ, наблюдалось больше антисаккадных ошибок (40,6\%) по сравнению с контролем $(23,4 \%$, Р<0,04). Сделан вывод, что эти аномалии могут указывать на неупорядоченную кортикальную и подкорковую саккадическую регуляцию, либо на подпороговые нарушения зрения, или происходить в результате более широкой связанной с заболеваниями нейродегенерации.

R. Hua et al. [25] используя EDI-SDOCT - метод, позволяющий провести глубинную визуализацию решетчатой пластинки склеры [30], исследовали 112 глаз с препериметрической глаукомой, но нормальной толщиной перипапиллярной сетчатки (диагноз был поставлен только на основании субъективной офтальмологической оценки). Применив так называемый асимметричный анализ заднего полюса глаза, включающий макулярную область сетчатки, параметры мембраны Бруха и склерального канала нервных волокон, авторы предложили использовать такие параметры, как форма склерального канала, исчезновение клеток пигментного эпителия, дистанция между мембраной Бруха и ДЗН), считая их ранними индикаторами поражения макулярной области сетчатки при препериметрической глаукоме.

J.Moreno at al. [39] с помощью Cirrus ОСТ провели анализ параметров ганглиозных клеток макулы и перипапиллярной сетчатки в 265 глазах с офтальмогипертензией без прогрессирования структурных изменений и с прогрессированием, которые были отнесены к группе препериметрической глаукомы. Был проведен подсчет количества патологических параметров, который показал, что чаще всего наблюдались единичные патологические изменения (16,6\%), а 3 и более патологических параметров наблюдались только в $4,2 \%$.

Y. Jung et al. [27], проведя сравнительные исследования 62 пациентов с помощью стандартной автоматизированной периметрии (SAP-24), периметрии с удвоенной частотой (FDT 10-2 и FDT 24-2), показали, что самая высокая корреляция была найдена для FDT 10-2 ( $r=0,544, P<0,001)$, затем FDT 24-2 ( $r=0,433, P=0,002)$ и SAP ( $r=0,346, P=0,007)$. 
Они считали, что причиной является большее количество контрольных точек в макулярной области сетчатки (32) по сравнению с SAP-24 (12).

S. Kim et al. [31], используя оптическую когерентную томографию и ОКТ-А ангиографию, провели исследование плотности перипапиллярных сосудов в парных глазах с односторонней нормотензивной глаукомой, препериметрической глаукомой и нормальных глазах. Они пришли к заключению, что глаза с препериметрической глаукомой и нормальные глаза имеют одинаковую плотность микроциркуляторного русла в перипапиллярной области с дефектом слоя нервных волокон, в то время как в глазах с периметрической глаукомой наблюдалось значительное уменьшение плотности сосудов в зоне истончения сетчатки. Это свидетельствует о том, что микрососудистые изменения могут быть вторичными по отношению к дегенерации нервных волокон.

Б. Ангелов и К. Петрова [2] обследовали 353 глаза, разделенные на 6 групп: офтальмогипертензия (32 глаза), препериметрическая глаукома (46), начальная глаукома (104), развитая глаукома (54), далеко зашедшая глаукома (60) и клинически здоровые глаза (57), используя SAP и OKT (RTVue-100). Исследования показали, что средняя толщина перипапиллярной сетчатки в препериметрической глаукоме (ППГ) заметно отличалась от нормальных глаз $(91,5 \mu \mathrm{m}$ и 108,3 $\mu \mathrm{m})$, но была ближе к начальной глаукоме $(91,5 \mu \mathrm{m}$ и $88,4 \mu \mathrm{m})$. То же наблюдалось и для средней толщины комплекса ганглиозных клеток $(86,6$ $\mu \mathrm{m}$ в ППГ и 102,5 $\mu \mathrm{m}$ в норме, 86,6 $\mu \mathrm{m}$ в ППГ и 84,3 $\mu \mathrm{m}$ в начальной глаукоме. Процент глобальных потерь комплекса ганглиозных клеток составил 10,94\% в ППГ и 1,66\% в норме, а в начальной глаукоме соответственно 10,94\% и 13,64\%.

Точно такое же исследование было проведено T. Audogan et al. [11] за исключением того, что кроме исследования сетчатки, они провели анализ параметров ДЗН, которые подтвердили тенденцию, наблюдавшуюся предыдущими авторами. Так, например, параметр rim area в группах нормы, препериметрической глаукомы и начальной глаукомы показал следующие данные: $1,66 \mathrm{~mm}^{2}-1,26 \mathrm{~mm}^{2}-1,14 \mathrm{~mm}^{2}$ соответственно, rim vol $0,24 \mathrm{~mm}^{3}-0,12 \mathrm{~mm}^{3}-0,10 \mathrm{~mm}^{3}$, cup/disc area $-0,51-0,69-0,72$ соответственно.

Н.И. Курышева и соавт. [3,4] провели комплексное исследование глаз с периметрической и препериметрической глаукомой, а также здоровых глаз, используя RTVue-100-OCT для анализа перипапиллярной сетчатки и комплекса ганглиозных клеток, ОСТ - ангиографию для исследования регионального кровотока и толщины хориоидеи. Была выявлена равная диагностическая ценность таких параметров, как средняя толщина слоя нервных волокон перипапиллярной сетчатки (RNFL), средняя толщина комплекса ганглиозных клеток (GCC) и потеря объема локальных и глобальных потерь GCC.

H. Inuzuka et al. [22] через 3 года наблюдения за 77 пациентами (77 глаз) с препериметрической глаукомой, используя SAP и SDOCT, выявили в 10 глазах (13\%) значительное уменьшение толщины перипапиллярной сетчатки и комплекса ганглиозных клеток в нижних секторах, и только в этой группе средняя величина ВГД составила 
$15,3 \pm 2,0$ мм рт. ст. В отличие от остальных $(13,5 \pm 2,6), \quad \mathrm{P}=0,042$. Указывается на необходимость тщательного мониторинга пациентов с препериметрической глаукомой.

H. Kim et al. [32] провели длительное наблюдение (более 6 лет) за пациентами с препериметрической глаукомой без кровоизлияний в диске и с наличием кровоизлияний и установили, что в глазах с геморрагиями диска интервал появления дефектов в поле зрения был значительно короче (45,4 месяца), чем при их отсутствии (73,3 месяца) $(P=0,042)$.

Y. Shiga et al. [49] провели лазерную спекл-флуорографию для исследования средней скорости кровотока и индекса капиллярного кровотока в перипапиллярной сетчатке здоровых глаз и у пациентов с препериметрической и нормотензивной глаукомой. Было выявлено значительное уменьшение кровотока в двух последних группах по сравнению с нормальными глазами $(\mathrm{P}=0,001)$.

H. Akil et al. [9] исследовали толщину хориоидеи и ее корреляцию c RNFL и комплексом ганглиозных клеток (GCC) при глаукоме, препериметрической глаукоме и в здоровых глазах с помощью swept-source ОСТ. Средняя толщина хориоидеи в перипапиллярной области сетчатки составила $117 \pm 41,7 \mu \mathrm{m}, 127,7 \pm 40,1 \mu \mathrm{m}$ и 120,8 $\pm 35,4 \mu \mathrm{m}$ соответственно, со слабой и умеренной корреляцией между параметрами $(0,341-0,410-0,346)$. Средняя толщина хориоидеи в макулярной области во всех группах практически не различались $(181,5 \pm 70,5 \mu \mathrm{m} ; 187,4 \pm 65,5 \mu \mathrm{m} ; 185,4 \pm 76,4 \mu \mathrm{m})$.

Sawada et al. [46] наблюдали 130 пациентов (130 глаз) с диагнозом препериметрическая нормотензивная глаукома и в 54,6\% из них через 5 лет обнаружили геморрагии по краю диска, повышение ВГД и ухудшение поля зрения. Авторы считают, что главной причиной ухудшения поля зрения является не флюктуация, а стойкое повышение среднего ВГД.

F. Daga et al. [18] считают, что в отличие от периметрической глаукомы, препериметрическая глаукома не влияет на качество жизни пациента, но является сигналом, предупреждающим о ее развитии.

A. Kreuz et al. [33] анализировали результаты исследования макулярной и мультифокальной электроретинографии в здоровых глазах, а также в глазах с препериметрической глаукомой по данным FD-OCT и глаукомой с патологическими изменениями параметра полуполей по данным SAP. Было выявлено заметное снижение по сравнению с нормой среднего Р50 пика при мультифокальной ЭРГ в группах с ППГ и глаукомой, в то время как изменения чувствительности и лабильности сетчатки были обнаружены только при глаукоме. Была также выявлена заметная корреляция ЭРГ с толщиной RNFL и слоя ганглиозных клеток в макулярной области сетчатки.

M. Suh et al. [45] исследовали плотность микрососудов хориоидеи с помощью оптической когерентной томографии (ОКТ-А) и показали, что плотность микрососудистой сети 
хориоидеи была значительно ниже в глаукомных глазах с очаговыми дефектами сетчатки, чем в глазах с препериметрической глаукомой без очаговых дефектов сетчатки, особенно в верхне-височном и нижне-височных секторах. Более низкая плотность сосудов коррелировала с расположением дефекта в сетчатке.

S. Kaushik et al. [28] с помощью оптической когерентной томографии (Cirrus OCT) провели сравнительный анализ диагностических возможностей комплекса ганглиозных клеток и толщины слоя нервных клеток перипапиллярной сетчатки у 275 больных с ранней глаукомой, подозрением на глаукому и здоровых пациентов и не выявили видимых различий между ними относительно препериметрической глаукомы (группа с подозрением на глаукому).

Nakano N. et al. [42], чтобы визуализировать слой клеток макулярного ганглия (GCL) и измерить его толщину в нормальных глазах и глазах с препериметрической глаукомой, использовали новый метод оптической когерентной томографии (Speckle noise-reduced SD-OCT imaging), который позволяет не только отчетливо видеть изображения макулярной сети ганглиозных клеток, но и определять ее толщину.

Rao H. et al. [43] оценивали способность параметров головки зрительного нерва (ONH), слоя нервных волокон сетчатки (RNFL) и комплекса ганглиозных клеток (GCC) с помощью оптического когерентного томографа (SDOCT) при обнаружении препериметрической глаукомы с большими экскавациями диска. Способность параметров SDOCT различать препериметрическую глаукому глаза от глаз с большой физиологической экскавацией оценивали по результатам ROC-анализа. Авторы сделали вывод, что диагностические возможности параметров ДЗН, RNFL и GCC для дифференциации глаз с предпериметрической глаукомой от контрольных глаз с большими физиологическими экскавациями были лишь умеренными.

Lee W.J. et al. [34,35] провели анализ эффективности swept-source optical coherence tomography (SS-OCT) для выявления мест расположения значительного снижения чувствительности поля зрения и прогнозирования возможных изменений у 43 пациентов с препериметрической глаукомой (43 глаза), которые наблюдались каждые 6 месяцев в течение минимум 2 лет. В 19 из 43 глаз с препериметрической глаукомой (44,2\%) было выявлено значительное снижение исходного поля зрения в зонах структурных изменений на картах вероятности SS-OCT. В 16 из 43 глаз (37,2\%) в течение периода наблюдения наблюдались последующие изменения поля зрения VF в областях изменения карты вероятности SS-OCT. Был сделан вывод, что структурные изменения на картах вероятности SS-OCT могут обнаружить или предсказать изменения поля зрения, используя SAP, a тщательное сравнение карт вероятности с результатами SAP может быть полезным для диагностики и мониторинга пациентов с ППГ в клинических условиях. 


\section{Заключение}

Когда мы впервые встретили в литературе термин «препериметрическая глаукома», то не могли понять его смысл, тем более что в первых публикациях почти всегда он звучал как «препериметрическая первичная открытоугольная глаукома». Возникал вопрос, можно ли ставить в диагнозе слово «глаукома», давно известное для населения как причина необратимой слепоты, при полном отсутствии каких-либо изменений остроты зрения и полей зрения. И только после тщательного изучения всех доступных для нас работ российских и зарубежных офтальмологов упоминавших препериметрическую глаукому мы нашли ему соответствующее место в классификации глаукомы.

Главным является четкое определение термина препериметрическая глаукома, как результата точного математического анализа патологических изменений параметров диска зрительного нерва, перипапиллярной сетчатки и комплекса ганглиозных клеток макулярной области сетчатки на фоне умеренного повышения ВГД (более 21 мм рт.ст.) и нормального состояния центрального поля зрения (MD не менее $-2,0 \mathrm{~dB}$ ).

Исследования, проведенные с помощью различных моделей оптической когерентной томографии (RTVue-100 OCT, Cirrus OCT, Spectralis SD OCT и др.) и Гейдельбергской лазерной ретинотомографии (HRT 2, HRT 3) показали, что в большинстве работ параметры диска зрительного нерва и сетчатки в группе глаз с препериметрической глаукомой статистически достоверно отличались от здоровых глаз, в то же время такого различия с группой глаз с начальной глаукомой не наблюдалось.

Не было выявлено заметного различия в информативности параметров перипапиллярной сетчатки, комплекса ганглиозных клеток макулярной области сетчатки и параметров ДЗН при препериметрической глаукоме, независимо от использованного метода исследования $[2,11,13,26,40,44]$, хотя имеются работы, свидетельствующие о преимуществе таких параметров как процент объемных потерь ганглиозных клеток макулярной области сетчатки [3,13].

В последние годы появилось много работ, освещающих клиническую характеристику глаз с препериметрической глаукомой, а именно: исследование кровотока и плотности микроциркулярных сосудов в хориоидее (ОСТ-ангиография) $[4,9,17,31,49]$, глубинная визуализация решетчатой пластинки склеры (EDI-SDOCT) [25], электроретинографические и окулографические исследования и другие методы, которые в большинстве случаев показывают некоторое отличие от глаукомы $[33,41]$.

Главная роль при конвергенции препериметрической глаукомы в начальную глаукому принадлежит состоянию центрального поля зрения. При этом чаще всего используется стандартная автоматизированная периметрия (SAP) по программе HFA 30-2 и 24-2, Octopus G1. Однако имеются работы, указывающие на преимущества таких методов исследования поля зрения как периметрия с удвоенной частотой (FDT-10) [16,20,21,24,51]. 
Работ по длительному наблюдению за пациентами с препериметрической глаукомой немного, но они четко указывают на более частые и более быстрые патологические изменения параметров диска по сравнению с нормальными глазами [22,32,46].

Точку зрения различных авторов можно выразить такими словами: препериметрическая глаукома является сложной клинической ситуацией, и ее управление осложняется недостатками диагностических тестов, доступных в настоящее время; в отличие от периметрической глаукомы, препериметрическая глаукома не влияет на качество жизни пациента, но является сигналом, предупреждающим о ее развитии [18]; до сих пор нет единого мнения по поводу патогенеза, диагноза и политики в отношении лечения препериметрической глаукомы [8]. Последние авторы ссылаются на работу Weinreb et al. [53], в которой предлагалось использовать термин «Glaucoma Continuum», указывающего на прогрессирующий характер глаукомы в виде серии непрерывных и необратимых событий, начиная с гибели ганглиозных клеток сетчатки, затем прогрессирующей препериметрической глаукомы с морфологическими изменениями ДЗН перипапиллярной сетчатки, приводящими к постепенному ухудшению поля зрения. Мы согласны с таким подходом, поскольку наши последние исследования полностью с ними согласуются [5-7].

Ниже приводим иллюстрацию классической препериметрической глаукомы пациента Б., 56 лет.

Vis OD $=0.9 P_{0}=17-23$ мм рт. ст. Биометрия $-23,95$ мм

Vis OS $=0.9 P_{0}-19-24$ мм рт. ст. Биометрия $-24,30$ мм 
Puc. 1. Результаты ОСT-RTVue-100. Выраженные патологические изменения почти всех параметров ДЗН в правом глазу и заметно меньшие в левом глазу.

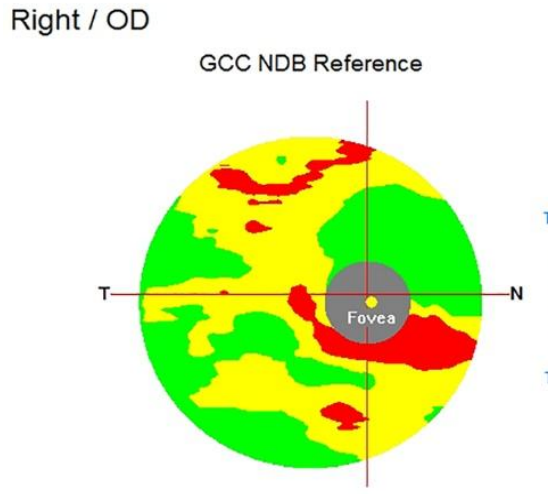

Left / OS

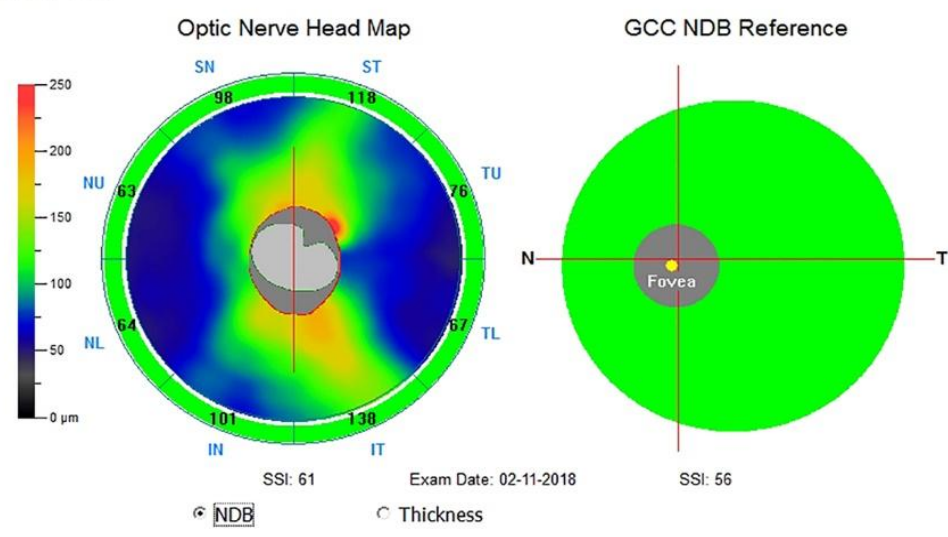

ONH/GCC OU Report
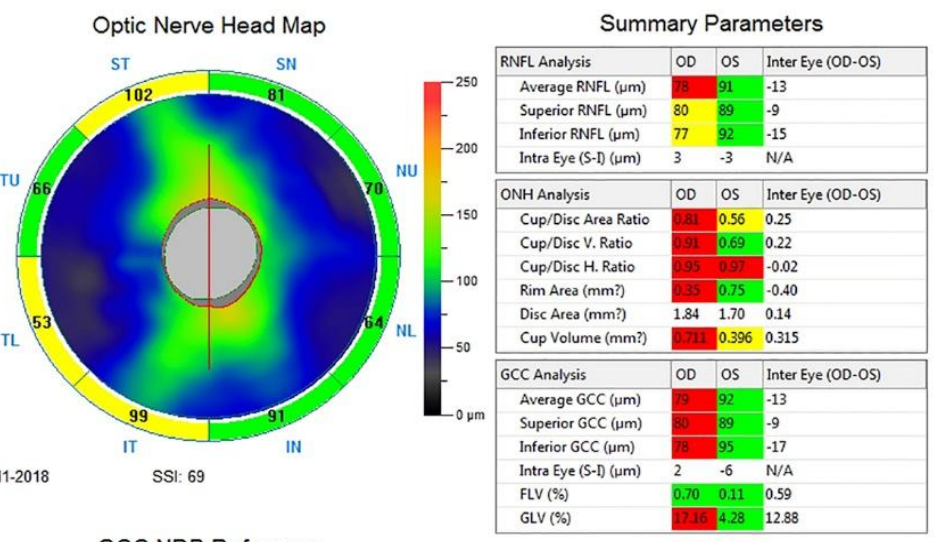

TSNIT NDB Reference

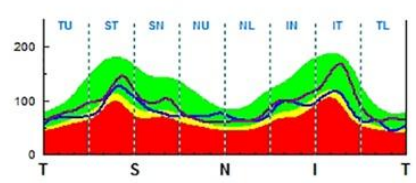

TSNIT Symmetry Plot
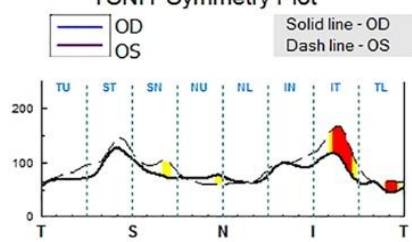

PUс. 2. Результаты HRT 3. Выраженные патологические изменения параметров диска в правом глазу и немного меньше в левом глазу.

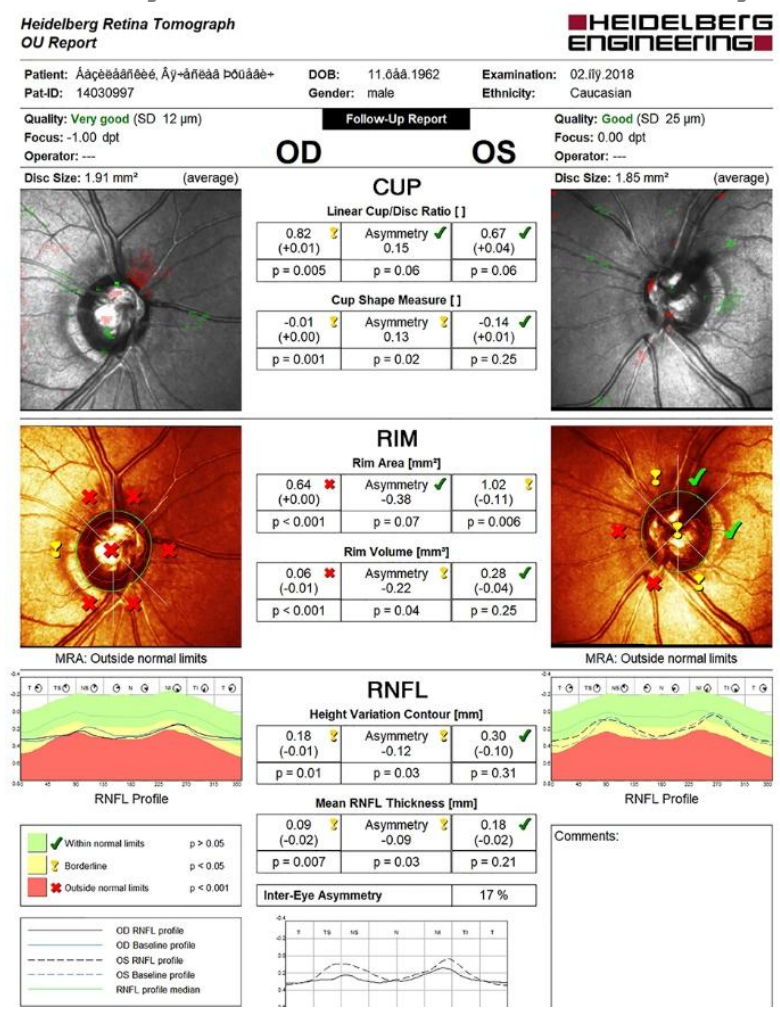

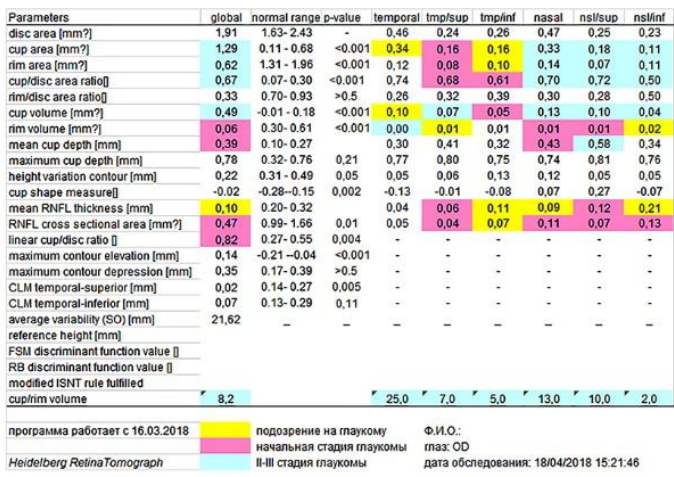

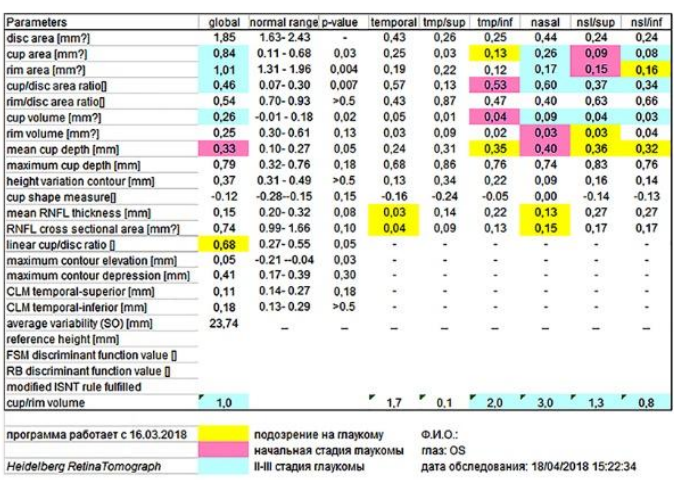


Puc. 3. Компьютерная периметрия центрального поля зрения обоих глаз по методу HFA 30-2 не выявила никаких патологических изменений.

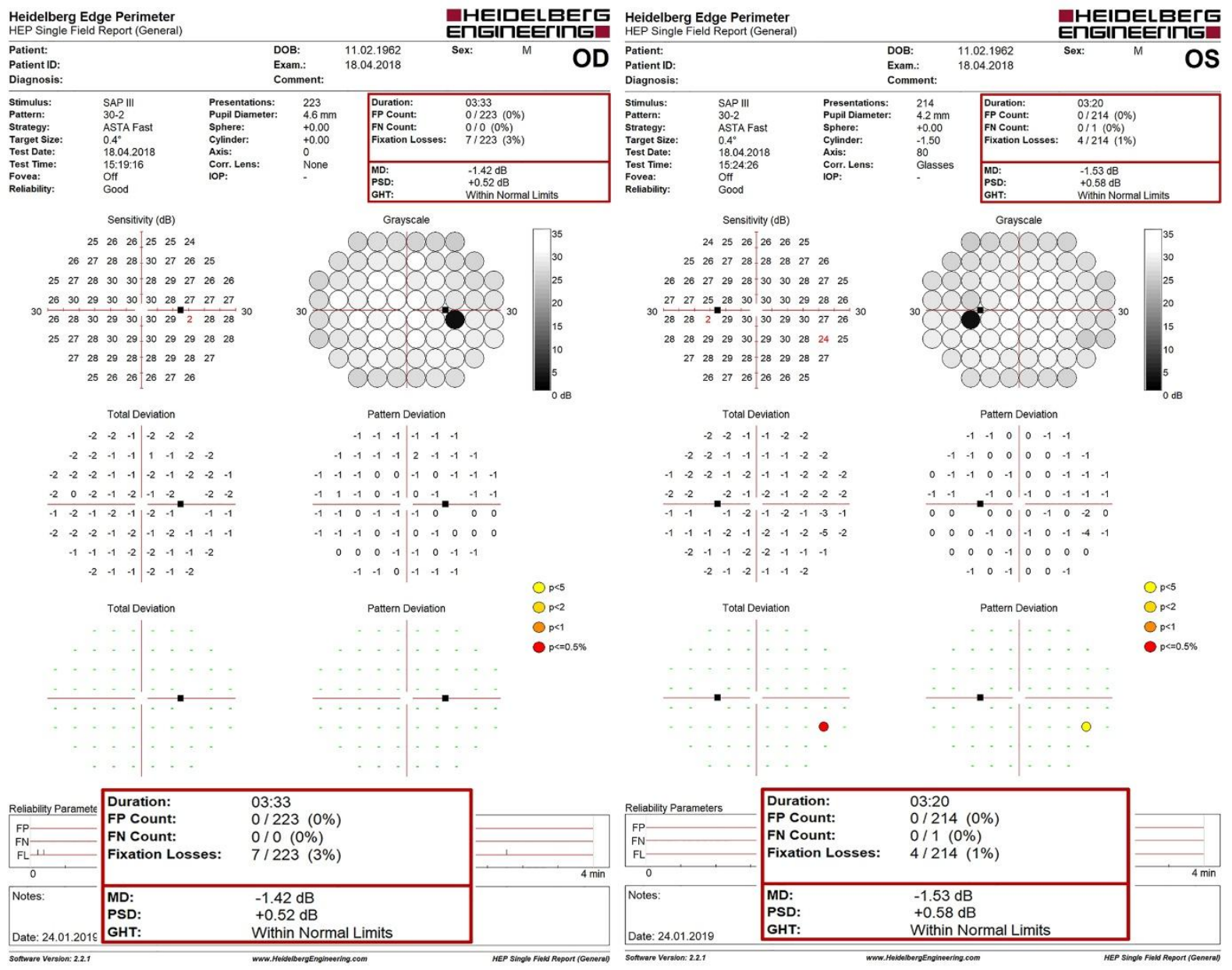

\section{Список литературы}

1. Акопян В.С., Семенова Н.С., Филоненко И.В., Цысарь М.А. Оценка комплекса ганглиозных клеток сетчатки при первичной открытоугольной глаукоме. Офттальмология2010; 8(1): 20-26.

2. Ангелов Б., Петрова К. Оптическая когерентная томография и её роль в диагностике глазной гипертензии, препериметрической и периметрической глаукомы.Офртальмология 2015; 12(1): 46-56.

3. Курышева Н.И., Паршунина О.А., Арджеинишвили Т.Д. Новые технологии в диагностике первичной открытоугольной глаукомы. Национальный журнал глаукома 2015; 14(2): 22-31.

4. Курышева Н.И., Паршунина О.А., Маслова Е.В. Диагностическая значимость исследования глазного кровотока в раннем выявлении первичной открытоугольной глаукомы. Национальный журнал глаукома 2015; 14(3): 19-29.

5. Мачехин В.А., Фабрикантов О.Л. Цветная топография патологических параметров ДЗН с помощью лазерного сканирующего ретинотомографа HRT III. Bulgarian Forum Glaucoma. Edition of the National Academy Glaucoma Foundation 2014; 4 (1): 13-20.

6. Мачехин В.А., Фабрикантов О.Л. К чему обязывает офтальмолога диагноз "подозрение на глаукому". Медицина 2017; (3): 108-124. 
7. Львов В.А., Фабрикантов О.Л., Мачехин В.А. Сравнительная оценка результатов исследования глаукомы с помощью Гейдельбергской лазерной ретинотомографии (HRT-3) и оптической когерентной томографии (RTVUE-100 ОСТ). Вестник ВолгГМУ 2018; 68(4): 21-24.

8. Aizawa N., Kunikata H., Shiga Y. et al. Preperimetric Glaucoma Prospective Observational Study (PPGPS): Design, baseline characteristics, and therapeutic effect of tafluprost in preperimetric glaucoma eye. PLoS One 2017; 12(12): e0188692. doi:10.1371/journal.pone.0188692.

9. Akil H., Al-Sheikh M., Falavarjani K.G. et al. Choroidal thickness and structural glaucoma parameters in glaucomatous, preperimetric glaucomatous, and healthy eyes using swept-source OCT. Eur J Ophthalmol 2017; 27(5): 548-554. doi: 10.5301/ejo.5000926.

10. Asaoka R., Iwase A., Hirasawa K. et al. Identifying "Preperimetric" Glaucoma in Standard Automated Perimetry Visual Fields. Invest Ophthalmol Vis Sci 2014; 55: 7814-7820. doi:10.1167/iovs.14-15120.

11. Aydoğan T., Betül i., Akçay S. et al. Evaluation of spectral domain optical coherence tomography parameters in ocular hypertension, preperimetric, and early glaucoma. Indian J Ophthalmol 2017; 65(11): 1143-1150.

12. Baraibar B., Sánchez-Cano A., Pablo L.E., Honrubia F.M. Preperimetric glaucoma assessment with scanning laser polarimetry (GDx VCC): analysis of retinal nerve fiber layer by sectors. J Glaucoma 2007; 16(8): 659-664.

13. Begum V.U., Addepalli U.K., Yadav R.K. et al. Ganglion Cell-Inner Plexiform Layer Thickness of High Definition Optical Coherence Tomography in Perimetric and Preperimetric Glaucoma. Invest Ophthalmol Vis Sci 2014; 55 : 4768-4775. doi: 10.1167/iovs.14-14598.

14. Begum V.U., Addepalli U.K., Senthil S., et al. Optic nerve head parameters of high-definition optical coherence tomography and Heidelberg retina tomogram in perimetric and preperimetric glaucoma. Indian $J$ Ophthalmol 2016; 64(4): 277-284.

15. Burk R.O., Rohrschneider K, Takamoto T, et al. Laser scanning tomography and stereophotogrammetry in three-dimensional optic disc analysis. Graefes Arch Clin Exp Ophthalmol 1993; 231: 193-198.

16. Choi J.A., Lee N.Y., Park C.K. Interpretation of the Humphrey Matrix 24-2 test in the diagnosis of preperimetric glaucoma. Jpn J Ophthalmol 2009; 53(1): 24-30. doi:10.1007/s10384-008-0604-0. Epub 2009 Jan 30.

17. Cennamo G., Montorio D., Velotti N. Optical coherence tomography angiography in preperimetric open angle glaucoma. Graefes Arch Clin Exp ophthalmol 2017; 255(9): 1797-1793. doi: 10.1007/s00417-017-3709-7.

18. Daga F.B., Gracitelli C.P.B., Diniz-Filho A. et al. Is vision-related quality of life impaired in patients with preperimetric glaucoma? Br J Ophthalmol 2018; Available at: www.pubfacts.com/detail/30049801/Is-visionrelated-quality-of-life-impaired-in-patients-with-preperimetric-glaucoma. doi: 10.1136/bjophthalmol-2018312357.

19. Dichtl A., Jonas J.B., Mardin C.Y. Comparison between tomographic scanning evaluation and photographic measurement of the neuroretinal rim. Am J Ophthalmol 1996; 121: 494-501.

20. Ferreras A., Polo V., Joser M. Larrosa et al. Can Frequency-doubling Technology and Short-wavelength Automated Perimetries Detect Visual Field Defects Before Standard Automated Perimetry in Patients with Preperimetric Glaucoma? J. Glaucoma 2007; 16: 372-383.

21. Hirashima T., Hangai M., Nukada M. et al. Frequency-doubling technology and retinal measurements with spectral-domain optical coherence tomography in preperimetric glaucoma.Graefes Arch Clin Exp Ophthalmol 2013; 251(1): 129-37. doi: 10.1007/s00417-012-2076-7.

22. Inuzuka H., Kawase K., Sawada A. et al. Development of Glaucomatous Visual Field Defects in Preperimetric Glaucoma Patients Within 3 Years of Diagnosis. Journal of Glaucoma 2016; 25(6): e591e595. doi: 10.1097/IJG.0000000000000260 
23. Hollo G., Szabo A., Vargha P. Scanning laser polarimetry versus frequency-doubling perimetry and conventional threshold perimetry: Changes during a 12-month follow up in preperimetric glaucoma. A pilot study. Acta Ophthalmol Scand 2001; 79: 403-407.

24. Horn F.K., Mardin C.Y., Bendschneider D. et al. Frequency doubling technique perimetry and spectral domain optical coherence tomography in patients with early glaucoma. Eye 2011; 25: 17-29.

25. Hua R., Gangwani R., Guo L. et al. Detection of preperimetric glaucoma using Bruch membrane opening, neural canal and posterior pole asymmetry analysis of optical coherence tomography. Scientific Reports 2016; (6): 21743. doi: 10.1038/srep21743.

26. Jeoung J.W., Park K.H. Comparison of Cirrus OCT and Stratus OCT on the ability to detect localized retinal nerve fiber layer defects in preperimetric glaucoma. Invest Ophthalmol Vis Sci2010; 51(2): 938-45. doi: 10.1167/iovs.083335.

27. JungY., Park H-Y., Park Y.R. et al. Usefulness of 10-2 Matrix Frequency Doubling Technology Perimetry for Detecting Central Visual Field Defects in Preperimetric Glaucoma Patients. Scientific reports 2017; (7): 14622. doi:10.1038/s41598-017-15329-1.

28. Kaushik S., Kataria P., Jain V. et al. Evaluation of macular ganglion cell analysis compared to retinal nerve fiber layer thickness for preperimetric glaucoma diagnosis. Indian J Ophthalmo/2018; 66(4): 511 516. doi: 10.4103/ijo.IJO_1039_17.

29. Kim H.G., Heo H., Park S.W. Comparison of scanning laser polarimetry and optical coherence tomography in preperimemetric glaucoma. Optom Vis Sci 2011; 88(1): 124-129. doi:1097/OPX.0b013e3181fdef9c.

30. Kim T.W., Kagemann L., Michaël J. A. et al. Imaging of the Lamina Cribrosa in Glaucoma: Perspectives of Pathogenesis and Clinical Applications. Curr Eye Res 2013; 38(9): 903-909.doi:10.3109/02713683.2013.800888.

31. Kim S.B., Lee E.J., Han J.C et al. Comparison of peripapillary vessel density between preperimetric and perimetric glaucoma evaluated by OCT-angiography. PLOS ONE 2017; 12(8): e0184297. doi: 10.1371/journal.pone.018429.

32. Kim H.J., Song Y.J', Kim Y.K. et al. Development of visual field defect after first-detected optic disc hemorrhage in preperimetric open-angle glaucoma. J Ophthalmol 2017; 61(4): 307-313. doi: 10.1007/s10384-017-0509-x.

33. Kreuz A.C., de Moraes C.G., Hatanaka M. et al Macular and Multifocal PERG and FD-OCT in Preperimetric and Hemifield Loss Glaucoma. J Glaucoma 2018; 27(2): 121-132. doi:10.1097/IJG.0000000000000857.

34. Lee W.J., Kim Y.K., Jeoung J.W. et al._Can Probability Maps of Swept-Source Optical Coherence Tomography Predict Visual Field Changes in Preperimetric Glaucoma? InvestOphthalmol Vis Sci. 2017; 58(14): $6257-$ 6264. doi: 10.1167/iovs.17-22697.

35. Lee W.J., Na K.I., Kim Y.K. et al. Diagnostic Ability of Wide-field Retinal Nerve Fiber Layer Maps Using SweptSource Optical Coherence Tomography for Detection of Preperimetric and Early Perimetric Glaucoma. Glaucoma 2017; 26(6): 577-585. doi:10.1097/IJG.0000000000000662.

36. Lisboa R., Leite M.T., Zangwill L.M. et al. Diagnosing Preperimetric Glaucoma with Spectral Domain Optical Coherence Tomography Ophthalmology 2012; 119(11): 2261-2269. doi:10.1016/j.ophtha.2012.06.009.

37. Mardin C.Y., Horn F.K., Jonas J.B. et al, Preperimetric glaucoma diagnosis by confocal scanning laser tomography of the optic disc. Br J Ophthalmol 1999; 83: 299-304.

38. Mikelberg F.S., Parfitt C.M., Swindale N.V. et al. Ability of the Heidelberg retina tomograph to detect early glaucomatous field loss. J Glaucoma 1995; 4: 242-247. 
39. Moreno-Monta J., Garcia-Nieva A., Osio I.A. et al. Evaluation of RETICs Glaucoma Diagnostic Calculators in Preperimetric Glaucoma. Trans Vis Sci Tech 2018; 7(6): 13. doi:10.1167/tvst.7.6.13.

40. Na J.H., Lee K., Lee J.R., Baek S. et al Detection of macular ganglion cell loss in preperimetric glaucoma patients with localized retinal nerve fibre defects by spectral-domain optical coherence tomography. Clin Exp Ophthalmol 2013; 41(9):870-80. doi:10.1111/ceo.12142.

41. Najjar R.P., Sharma S., Drouet M. et al. Disrupted Eye Movements in Preperimetric Primary Open Angle Glaucoma. Invest Ophthalmol Vis Sci 2017; 58: 2430-2437. doi: 10.1167/iovs.16-21002.

42. Nakano N., Hangai M., Nakanishi H. et al. Macular ganglion cell layer imaging in preperimetric glaucoma with speckle noise-reduced spectral domain optical coherence tomography. Ophthalmology 2011; 118(12): 241426. doi: 10.1016/j.ophtha.2011.06.015.

43. Rao H.L., Addepalli U.K., Chaudhary S. et al. Ability of different scanning protocols of spectral domain optical coherence tomography to diagnose preperimetric glaucoma. Invest. Ophthalmol Vis Sci 2013; 54: 7252 7257. doi: 10.1167/iovs.13-12731.

44. Rolle T., Briamonte C., Curto D., Grignolo F.M. Ganglion cell complex and retinal nerve fiber layer measured by fourier-domain optical coherence tomography for early detection of structural damage in patients with preperimetric glaucoma Clinical Ophthalmology 2011; (5): 961-969.

45. Suh M.H., Zangwill L.M., Isabel P. et al. Optical Coherence Tomography Angiography Vessel Density in Glaucomatous Eyes with Focal Lamina Cribrosa Defects. Ophthalmology2016; 123(11): 23092317. doi: 10.1016/j.ophtha.2016.07.023.

46. Sawada A., Manabe Y., Yamamoto T., Nagata C. Long-term clinical course of normotensive preperimetric glaucoma. Br J Ophthalmol 2017; 101(12): 1649-1653. doi:10.1136/bjophthalmol-2016-309401.

47. Schumann J.S., Hee M.R., Puliafito C.A. et al. Quantification of nerve fiber layer thickness in normal and glaucomatous eyes using optical coherence tomography. Arch Ophthalmol 1995; 113: 586-96.

48. Seol B.R., Jeoung J.W., Park K.H. Glaucoma Detection Ability of Macular Ganglion Cell-Inner Plexiform Layer Thickness in Myopic Preperimetric Glaucoma. Invest Ophthalmol Vis Sci2015; 56: 8306-8313. doi: 10.1167/iovs.1518141.

49. Shiga Y., Kunikata H., Aizawa N., et al. Optic Nerve Head Blood Flow, as Measured by Laser Speckle Flowgraphy, is Significantly Reduced in Preperimetric Glaucoma. Curr Eye Res2016; 41(11): 1447-

1453. doi: 10.3109/02713683.2015.1127974.

50. Shiga Y., Aizawa N., Tsuda S., et al. Preperimetric Glaucoma Prospective Study (PPGPS): Predicting Visual Field Progression with Basal Optic Nerve Head Blood Flow in Normotensive PPG Eyes. Transl Vis Sci Technol 2018; 7(1): 11. doi: $10.1167 /$ tvst.7.1.11.

51. Sriram P., Klistorner A., Graham S. et al. Optimizing the Detection of Preperimetric Glaucoma by Combining Structural and Functional Tests. Invest Ophthalmol Vis Sci 2015; 56: 7794-7800. doi: 10.1167/iovs.15-16721.

52. Tjon-Fo-Sang M.J., de Vries J., Lemji H.G. Measurement by nerve fiber analyzer of retinal nerve fiber layer thickness in normal subjects and patients with ocular hypertension. Am J Ophthalmol 1996; 122: 220-7.

53. Weinreb R.N., Friedman D.S., Fechtner R.D. et al. Risk assessment in the management of patients with ocular hypertension. Am J Ophthalmol 2004; 138: 458-467. doi:10.1016/j.ajo.2004.04.054. 


\section{Preperimetric glaucoma (literature review)}

Machekhin V. A. ${ }^{1,2}$

Doctor of Medicine, Chief Scientific Adviser ${ }^{1}$, Professor, Chair for Ophtalmology ${ }^{2}$

Fabrikantov O. L. ${ }^{1,2}$

Doctor of Medicine, Director ${ }^{1}$, Head, Chair for Ophtalmology ${ }^{2}$

L'vov V. A. ${ }^{1}$

Ophtalmologist

1 - Federal State Autonomous Institution "S.N.Fedorov National Medical Research Center "MNTK "Eye Microsurgery" of the Ministry of Health of the Russian Federation, Tambov branch, Tambov, Russian Federation

2 - Derzhavin Tambov State University, Medical Institute, Tambov, Russia

Corresponding author: Machekhin Vladimir; e-mail: naukatmb@mail.ru

Conflict of interest. None declared.

Funding. The study had no sponsorship.

\section{Summary}

The term "preperimetric glaucoma" first appeared in foreign literature at the end of the 20th century. Previous experience in analyzing the optic disc was mainly based on ophthalmoscopy, photography and stereophotography, planimetry and other difficult methods of investigation in glaucoma. The emergence of modern more accurate diagnostic methods allowed for the first time separating qualitative (subjective) and quantitative (objective) criteria for assessing the optic disc and the adjacent retina. It took years before ophthalmologists began to comprehend the meaning of the term and its role in glaucoma. This issue is the subject of this literature review, sources are presented in chronological order.

Key words: ophthalmology, preperimetric glaucoma, optic disc

\section{References}

1. Akopyan V.S., Semenova N.S., Filonenko I.V., Tsysar' M.A. Otsenka kompleksa ganglioznykh kletok setchatki pri pervichnoy otkrytougol'noy glaukome. [Evaluation of ganglion cell complex measurements in primary open-angle glaucoma]. Oftal'mologiya [Ophthalmology] 2011; 8(1): 20-26. (In Russ.)

2. Angelov B., Petrova K. Opticheskaya kogerentnaya tomografiya i eyo rol' v diagnostike glaznoy gipertenzii, preperimetricheskoy i perimetricheskoy glaukomy. [Optical coherence tomography and its role in the diagnosis of ocular hypertension, preperimetric and perimetric glaucoma]. Oftal'mologiya [Ophthalmology] 2015; 12(1): 46-56. (In Russ.)

3. Kurysheva N.I., Parshunina O.A., Ardzheinishvili T.D. Novyye tekhnologii v diagnostike pervichnoy otkrytougol'noy glaukomy. [New technologies in primary open-angle glaucoma diagnostics]. Natsional'nyy zhurnal glaucoma [National journal of glaucoma] 2015; 14(2): 22-31. (In Russ.)

4. Kurysheva N.I., Parshunina O.A., Maslova E.V. Diagnosticheskaya znachimost' issledovaniya glaznogo krovotoka $v$ rannem vyyavlenii pervichnoy otkrytougol'noy glaukomy. [Role of eye hemoperfusion in the progress of primary open-angle glaucoma]. Natsional'nyy zhurnal glaucoma [National journal of glaucoma] 2015; 14(3): 19-29. (In Russ.)

5. Machekhin V.A., Fabrikantov O.L. Tsvetnaya topografiya patologicheskikh parametrov DZN s pomoshch'yu lazernogo skaniruyushchego retinotomografa HRT III [Color topography of the pathologic parameters of the OD by 
means of the laser scanning retinotomograph HRT III.Bulgarian Forum Glaucoma. Edition of the National Academy Glaucoma Foundation 2014; 4(1): 13-20. (In Russ.)

6. Machekhin V.A., Fabrikantov O.L. K chemu obyazyvayet oftal'mologa diagnoz "podozreniye na glaukomu" [What is an ophthalmologist obliged to do in case of "suspected glaucoma" diagnosis]. Meditsina [Medicine] 2017; (3): 108-124. (In Russ.)

7. L'vov V.A., Fabrikantov O.L., Machekhin V.A. Sravnitel'naya otsenka rezul'tatov issledovaniya glaukomy s pomoshch'yu Geydel'bergskoy lazernoy retinotomografii (HRT-3) i opticheskoy kogerentnoy tomografii (RTVUE100 OCT). [Comparative assessment of glaucoma study outcomes using Heidelberg laser retinal tomography (HRT 3) and optical coherence tomography (RTVUE-100)]. Vestnik VolgGMU [Journal of VolgSMU] 2018; 68(4): 21-24. (In Russ.)

8. Aizawa N., Kunikata H., Shiga Y. et al. Preperimetric Glaucoma Prospective Observational Study (PPGPS): Design, baseline characteristics, and therapeutic effect of tafluprost in preperimetric glaucoma eye. PLoS One 2017; 12(12): e0188692. doi:10.1371/journal.pone.0188692.

9. Akil H., Al-Sheikh M., Falavarjani K.G. et al. Choroidal thickness and structural glaucoma parameters in glaucomatous, preperimetric glaucomatous, and healthy eyes using swept-source OCT. Eur J Ophthalmol 2017; 27(5): 548-554. doi: 10.5301/ejo.5000926.

10. Asaoka R., Iwase A., Hirasawa K. et al. Identifying "Preperimetric" Glaucoma in Standard Automated Perimetry Visual Fields. Invest Ophthalmol Vis Sci 2014; 55: 7814-7820. doi:10.1167/iovs.14-15120.

11. Aydoğan T., Betül i., Akçay S. et al. Evaluation of spectral domain optical coherence tomography parameters in ocular hypertension, preperimetric, and early glaucoma. Indian J Ophthalmol 2017; 65(11): 1143-1150.

12. Baraibar B., Sánchez-Cano A., Pablo L.E., Honrubia F.M. Preperimetric glaucoma assessment with scanning laser polarimetry (GDx VCC): analysis of retinal nerve fiber layer by sectors. J Glaucoma 2007; 16(8): 659-664.

13. Begum V.U., Addepalli U.K., Yadav R.K. et al. Ganglion Cell-Inner Plexiform Layer Thickness of High Definition Optical Coherence Tomography in Perimetric and Preperimetric Glaucoma. Invest Ophthalmol Vis Sci 2014; 55: 4768-4775. doi: 10.1167/iovs.14-14598.

14. Begum V.U., Addepalli U.K., Senthil S., et al. Optic nerve head parameters of high-definition optical coherence tomography and Heidelberg retina tomogram in perimetric and preperimetric glaucoma. Indian $\mathrm{J}$ Ophthalmol 2016; 64(4): 277-284.

15. Burk R.O., Rohrschneider K, Takamoto T, et al. Laser scanning tomography and stereophotogrammetry in three-dimensional optic disc analysis. Graefes Arch Clin Exp Ophthalmol 1993; 231: 193-198.

16. Choi J.A., Lee N.Y., Park C.K. Interpretation of the Humphrey Matrix 24-2 test in the diagnosis of preperimetric glaucoma. Jpn J Ophthalmol 2009; 53(1): 24-30. doi:10.1007/s10384-008-0604-0. Epub 2009 Jan 30.

17. Cennamo G., Montorio D., Velotti N. Optical coherence tomography angiography in preperimetric open angle glaucoma. Graefes Arch Clin Exp ophthalmol 2017; 255(9): 1797-1793. doi: 10.1007/s00417-017-3709-7.

18. Daga F.B., Gracitelli C.P.B., Diniz-Filho A. et al. Is vision-related quality of life impaired in patients with preperimetric glaucoma? Br J Ophthalmol 2018; Available at: www.pubfacts.com/detail/30049801/Is-visionrelated-quality-of-life-impaired-in-patients-with-preperimetric-glaucoma. doi: 10.1136/bjophthalmol-2018312357.

19. Dichtl A., Jonas J.B., Mardin C.Y. Comparison between tomographic scanning evaluation and photographic measurement of the neuroretinal rim. Am J Ophthalmol 1996; 121: 494-501. 
20. Ferreras A., Polo V., Joser M. Larrosa et al. Can Frequency-doubling Technology and Short-wavelength Automated Perimetries Detect Visual Field Defects Before Standard Automated Perimetry in Patients with Preperimetric Glaucoma? J. Glaucoma 2007; 16: 372-383.

21. Hirashima T., Hangai M., Nukada M. et al. Frequency-doubling technology and retinal measurements with spectral-domain optical coherence tomography in preperimetric glaucoma.Graefes Arch Clin Exp Ophthalmol 2013; 251(1): 129-37. doi: 10.1007/s00417-012-2076-7.

22. Inuzuka H., Kawase K., Sawada A. et al. Development of Glaucomatous Visual Field Defects in Preperimetric Glaucoma Patients Within 3 Years of Diagnosis. Journal of Glaucoma 2016; 25(6): e591e595. doi: 10.1097/IJG.0000000000000260,

23. Hollo G., Szabo A., Vargha P. Scanning laser polarimetry versus frequency-doubling perimetry and conventional threshold perimetry: Changes during a 12-month follow up in preperimetric glaucoma. A pilot study. Acta Ophthalmol Scand 2001; 79: 403-407.

24. Horn F.K., Mardin C.Y., Bendschneider D. et al. Frequency doubling technique perimetry and spectral domain optical coherence tomography in patients with early glaucoma. Eye 2011; 25: 17-29.

25. Hua R., Gangwani R., Guo L. et al. Detection of preperimetric glaucoma using Bruch membrane opening, neural canal and posterior pole asymmetry analysis of optical coherence tomography. Scientific Reports 2016; (6): 21743. doi: 10.1038/srep21743.

26. Jeoung J.W., Park K.H. Comparison of Cirrus OCT and Stratus OCT on the ability to detect localized retinal nerve fiber layer defects in preperimetric glaucoma. Invest Ophthalmol Vis Sci2010; 51(2): 938-45. doi: 10.1167/iovs.083335.

27. JungY., Park H-Y., Park Y.R. et al. Usefulness of 10-2 Matrix Frequency Doubling Technology Perimetry for Detecting Central Visual Field Defects in Preperimetric Glaucoma Patients. Scientific reports 2017; (7): 14622. doi:10.1038/s41598-017-15329-1.

28. Kaushik S., Kataria P., Jain V. et al. Evaluation of macular ganglion cell analysis compared to retinal nerve fiber layer thickness for preperimetric glaucoma diagnosis. Indian J Ophthalmo/2018; 66(4): 511516. doi: 10.4103/ijo.IJO_1039_17.

29. Kim H.G., Heo H., Park S.W. Comparison of scanning laser polarimetry and optical coherence tomography in preperimemetric glaucoma. Optom Vis Sci 2011; 88(1): 124-129. doi:1097/OPX.0b013e3181fdef9c.

30. Kim T.W., Kagemann L., Michaël J. A. et al. Imaging of the Lamina Cribrosa in Glaucoma: Perspectives of Pathogenesis and Clinical Applications. Curr Eye Res 2013; 38(9): 903-909.doi:10.3109/02713683.2013.800888.

31. Kim S.B., Lee E.J., Han J.C et al. Comparison of peripapillary vessel density between preperimetric and perimetric glaucoma evaluated by OCT-angiography. PLOS ONE 2017; 12(8): e0184297. doi: 10.1371/journal.pone.018429.

32. Kim H.J., Song Y.J', Kim Y.K. et al. Development of visual field defect after first-detected optic disc hemorrhage in preperimetric open-angle glaucoma. J Ophthalmol 2017; 61(4): 307-313. doi: 10.1007/s10384-017-0509-x.

33. Kreuz A.C., de Moraes C.G., Hatanaka M. et al Macular and Multifocal PERG and FD-OCT in Preperimetric and Hemifield Loss Glaucoma. J Glaucoma 2018; 27(2): 121-132. doi:10.1097/IJG.0000000000000857.

34. Lee W.J., Kim Y.K., Jeoung J.W. et al._Can Probability Maps of Swept-Source Optical Coherence Tomography Predict Visual Field Changes in Preperimetric Glaucoma? InvestOphthalmol Vis Sci. 2017; 58(14): $6257-$ 6264. doi: 10.1167/iovs.17-22697. 
35. Lee W.J., Na K.I., Kim Y.K. et al. Diagnostic Ability of Wide-field Retinal Nerve Fiber Layer Maps Using SweptSource Optical Coherence Tomography for Detection of Preperimetric and Early Perimetric Glaucoma. Glaucoma 2017; 26(6): 577-585. doi:10.1097/IJG.0000000000000662.

36. Lisboa R., Leite M.T., Zangwill L.M. et al. Diagnosing Preperimetric Glaucoma with Spectral Domain Optical Coherence Tomography Ophthalmology 2012; 119(11): 2261-2269. doi:10.1016/j.ophtha.2012.06.009.

37. Mardin C.Y., Horn F.K., Jonas J.B. et al, Preperimetric glaucoma diagnosis by confocal scanning laser tomography of the optic disc. Br J Ophthalmol 1999; 83: 299-304.

38. Mikelberg F.S., Parfitt C.M., Swindale N.V. et al. Ability of the Heidelberg retina tomograph to detect early glaucomatous field loss. J Glaucoma 1995; 4: 242-247.

39. Moreno-Monta J., Garcia-Nieva A., Osio I.A. et al. Evaluation of RETICs Glaucoma Diagnostic Calculators in Preperimetric Glaucoma. Trans Vis Sci Tech 2018; 7(6): 13. doi:10.1167/tvst.7.6.13.

40. Na J.H., Lee K., Lee J.R., Baek S. et al Detection of macular ganglion cell loss in preperimetric glaucoma patients with localized retinal nerve fibre defects by spectral-domain optical coherence tomography. Clin Exp Ophthalmol 2013; 41(9):870-80. doi:10.1111/ceo.12142.

41. Najjar R.P., Sharma S., Drouet M. et al. Disrupted Eye Movements in Preperimetric Primary Open Angle Glaucoma. Invest Ophthalmol Vis Sci 2017; 58: 2430-2437. doi: 10.1167/iovs.16-21002.

42. Nakano N., Hangai M., Nakanishi H. et al. Macular ganglion cell layer imaging in preperimetric glaucoma with speckle noise-reduced spectral domain optical coherence tomography. Ophthalmology 2011; 118(12): 241426. doi: 10.1016/j.ophtha.2011.06.015.

43. Rao H.L., Addepalli U.K., Chaudhary S. et al. Ability of different scanning protocols of spectral domain optical coherence tomography to diagnose preperimetric glaucoma. Invest. Ophthalmol Vis Sci 2013; 54: 7252 7257. doi: 10.1167/iovs.13-12731.

44. Rolle T., Briamonte C., Curto D., Grignolo F.M. Ganglion cell complex and retinal nerve fiber layer measured by fourier-domain optical coherence tomography for early detection of structural damage in patients with preperimetric glaucoma Clinical Ophthalmology 2011; (5): 961-969.

45. Suh M.H., Zangwill L.M., Isabel P. et al. Optical Coherence Tomography Angiography Vessel Density in Glaucomatous Eyes with Focal Lamina Cribrosa Defects. Ophthalmology2016; 123(11): 23092317. doi: 10.1016/j.ophtha.2016.07.023.

46. Sawada A., Manabe Y., Yamamoto T., Nagata C. Long-term clinical course of normotensive preperimetric glaucoma. Br J Ophthalmol 2017; 101(12): 1649-1653. doi:10.1136/bjophthalmol-2016-309401.

47. Schumann J.S., Hee M.R., Puliafito C.A. et al. Quantification of nerve fiber layer thickness in normal and glaucomatous eyes using optical coherence tomography. Arch Ophthalmol 1995; 113: 586-96.

48. Seol B.R., Jeoung J.W., Park K.H. Glaucoma Detection Ability of Macular Ganglion Cell-Inner Plexiform Layer Thickness in Myopic Preperimetric Glaucoma. Invest Ophthalmol Vis Sci2015; 56: 8306-8313. doi: 10.1167/iovs.1518141.

49. Shiga Y., Kunikata H., Aizawa N., et al. Optic Nerve Head Blood Flow, as Measured by Laser Speckle Flowgraphy, is Significantly Reduced in Preperimetric Glaucoma. Curr Eye Res2016; 41(11): 1447-

1453. doi: 10.3109/02713683.2015.1127974.

50. Shiga Y., Aizawa N., Tsuda S., et al. Preperimetric Glaucoma Prospective Study (PPGPS): Predicting Visual Field Progression with Basal Optic Nerve Head Blood Flow in Normotensive PPG Eyes. Transl Vis Sci Technol 2018; 7(1): 11. doi: 10.1167/tvst.7.1.11. 
51. Sriram P., Klistorner A., Graham S. et al. Optimizing the Detection of Preperimetric Glaucoma by Combining Structural and Functional Tests. Invest Ophthalmol Vis Sci 2015; 56: 7794-7800. doi: 10.1167/iovs.15-16721.

52. Tjon-Fo-Sang M.J., de Vries J., Lemji H.G. Measurement by nerve fiber analyzer of retinal nerve fiber layer thickness in normal subjects and patients with ocular hypertension. Am J Ophthalmol 1996; 122: 220-7.

53. Weinreb R.N., Friedman D.S., Fechtner R.D. et al. Risk assessment in the management of patients with ocular hypertension. Am J Ophthalmol 2004; 138: 458-467. doi:10.1016/j.ajo.2004.04.054. 